\title{
Meckel's Diverticulum Perforation Mimicking Gynaecologic Acute Abdomen
}

The Editor,

Sir,

A 28-year old multiparous woman was admitted to our Emergency Department with the complaints of severe pelvic pain (acute onset), nausea and vomiting. In her previous history, she had two deliveries via Caesarean section. Physical examination revealed guarding and rebound tenderness (widespread, but prominent in the lower quadrant) with normal vital signs. Laboratory investigations were within normal limits except increased white blood cell count $\left(18.800 / \mathrm{mm}^{3}\right.$ (91\% neutrophils), Normal ranges: 4000-10 000). Transvaginal ultrasound revealed dense content, septated, particulate free fluid in the pouch of Douglas, probably consistent with haemorrhagic. Endometrial thickness was $2 \mathrm{~mm}$ and bilateral hydrosalpynx was detected.

According to the patient's clinical situation, a definitive diagnoses of gynaecologic acute abdomen was established and explorative laparotomy was planned. A perforated Meckel's diverticulum (MD) was observed $90 \mathrm{~cm}$ proximally from the ileocecal valve (Figure). The diverticulum was resected along with $15 \mathrm{~cm}$ of ileum from both proximal and distal sides of the perforated area and entero-enteric anastomosis (end-to-end) was performed followed by abundant washing and cleaning of the abdominal cavity. Pathological examination reported ileal tissue with ulceration around a perforated diverticulum. The patient was discharged home on the tenth postoperative day with an uneventful recovery.

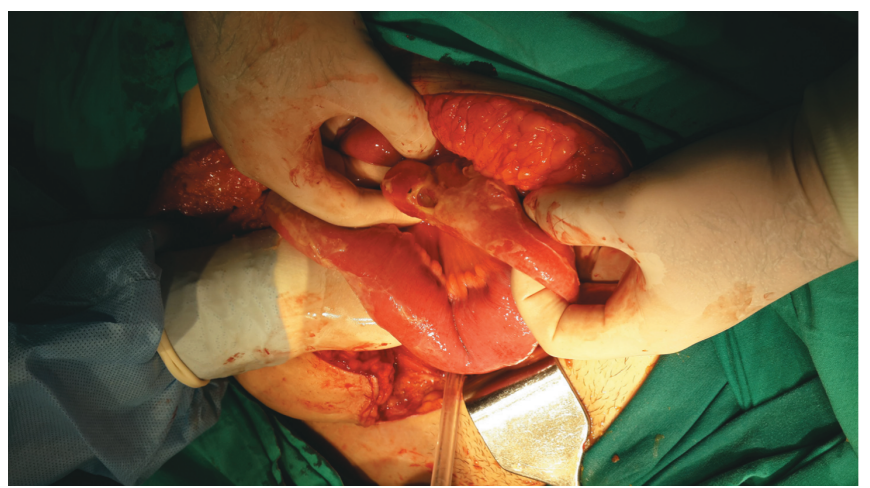

Figure: Intra-operative images designate Meckel's diverticulum.

Meckel's diverticulum occurs due to the incomplete obliteration of the omphalomesenteric duct during the $7^{\text {th }}$ week of gestation. Meckel diverticulum is the most common developmental anomaly of the gastrointestinal tract with two per- cent prevalence (1). Meckel's diverticulum is usually asymptomatic and incidentally found during laparotomy due to other gastrointestinal diseases. Furthermore, MD is more likely to be symptomatic in children than adults. Whereas, intestinal haemorrhage is the most common presentation of MD in children, intestinal obstruction is the most common in adult patients $(1,2)$. Moreover, previous studies reported that MD presents as intussusception, inflammation or diverticulitis, haemorrhage, and perforation, the last one being rare (3). In conclusion, herein, is presented an unusual case with perforated MD which can be symptomatic in adult patients but symptoms can mimic gynaecological acute abdomen.

Keywords: Gynaecologic acute abdomen, Meckel's diverticulum perforation, Turkey

B Akselim ${ }^{1}$, M Doğanay ${ }^{1}$, G Terzioğlu ${ }^{2}, H$ Demir $^{1}$, I Selçuk ${ }^{1}$

From: ${ }^{1}$ Department of Obstetrics and Gynecology and ${ }^{2}$ Department of General Surgery, Dr Zekai Tahir Burak Woman's Health Research and Education Hospital, Ankara, Turkey.

Correspondence: Dr B Akselim, Dr Zekai Tahir Burak Kadın Să̆lı̆̆l Ĕgitim ve Araştırma Hastanesi, 06230, Talatpasa Bulvari, Altindag Ankara, Turkey. Fax: +90 31231249 31, e-mail: burakakselim@hotmail.com

\section{REFERENCES}

1. Emre A, Akbulut S, Yilmaz M, Kanlioz M, Aydin BE. Double Meckel's Diverticulum Presenting as Acute Appendicitis: A Case Report and Literature Review. J Emer Med 2013; 44: e321-e4.

2. Canelas A, Neto A, Rodrigues A, Meguins LC, Rolo DF, Lobato MF. Perforation of Meckel's diverticulum by a chicken bone mimicking acute appendicitis. Case report. G Chir 2009; 30: 476-8.

3. Dumper J, Mackenzie S, Mitchell P, Sutherland F, Quan ML, Mew D. Complications of Meckel's diverticula in adults. Can J Sur 2006; 49: 353. 